\title{
Foucault (parcialmente) vindicado no Brasil central: sexualidade como um dos fundamentos da vida
}

\author{
- Vanessa Rosemary Lea \\ Universidade Estadual de Campinas, Campinas, São Paulo, Brasil
}

DOI 10.11606/issn.2316-9133.v24i24p427-440

resumo Ao se conviver com os Mebengokre (também conhecidos como Kayapó, de língua Jê), a presença da sexualidade permea todo o ambiente. É um dos assuntos favoritos das conversas e uma das fontes preferidas de prazer. No entanto, já em meados da década de 1990, os homens censuraram minhas conversas com as mulheres sobre sexualidade, designando-as como "fofoca" - inútil para fomentar projetos ou obter empregos. Em um curso para formação de professores bilíngues, em 2009, fui censurada novamente, desta vez por introduzir a questão da homossexualidade, sob a alegação de ser este um assunto de "branco". A sexualidade Mebengokre já suscitou questóes fantasiosas, como a figura da "especialista sexual paga", algo que reverberou na literatura internacional. Após meio século de referências esparsas a respeito da sexualidade Mebengokre, permanece a indagação sobre a possibilidade de abordá-la fora da perspectiva do exotismo.

palavras-chave Mebengokre-Kayapó; Sexualidade; Gênero; Aliança matrimonial; Ética de pesquisa.

Foucault (partially) vindicated in Central Brazil: sexuality as one of the fundaments of life

abstract By living among the Mebengokre (also known as Kayapó, of Jê language), it is easy to note the environment permeated with sexuality. It is a favourite topic of conversation and one of the main sources of pleasure. However, already in the mid-1990s, the men censored my conversations with the women about sexuality, designating them as "gossip" - useless for formulating projects or getting jobs. During a course for training bilingual teachers, in 2009, I was censored again, this time for introducing the homosexuality issue, with the allegation that it was a problem of "white people". Mebengokre's sexuality has alre- 
ady given rise to unrealistic issues, such as the character of a "paid sex specialist", something that reverberated in the international literature. After half century of sparse references to Mebengokre sexuality, the issue regarding the possibility of dealing with it without an exotic perspective remains.

keywords Mebengokre-Kayapó; Sexuality; Gender; Marriage alliance; Research ethics.

Ao reler o título preliminar do meu artigo "Foucault vindicado no Brasil Central: sexualidade como um dos fundamentos da vida", fiquei tentada a substituir a palavra sexualidade por sexo, mas me limitei a qualificar o verbo "vindicar". Nos cursos de parentesco que ministrei na Unicamp, sempre apontava para a ambiguidade do termo sexo: confunde dois sentidos bem distintos - sexo anatômico e o ato sexual (algo que não escapou à atençáo de Foucault). Junto com a leitura do primeiro volume da Histoire de la sexualité (1976), reli o que eu já havia escrito sobre sexualidade Mebengokre $^{1}$ (dois artigos sobre gênero [1994 e 2000], um sobre sexualidade [2013], um capítulo de livro sobre parentesco e dimorfismo sexual [2010] e outro sobre paternidade múltipla [2002]). Cheguei à conclusão de que já havia esgotado a apresentaçáo dos dados colecionados em campo. Fiquei táo fascinada pelo livro de Foucault, que eu não havia conseguido ler antes, que decidi vincular este artigo a alguns dos assuntos levantados nessa obra.

Em uma entrevista recente, Sherry Ortner (2015) comentou que sentia certa culpa ao discutir gênero na atualidade, perante a urgência de outros assuntos como a economia e o meio ambiente. Tal incômodo se impóe mais do que nunca na atual conjuntura socioeconômica e política do Brasil e do mundo, caracterizada por conservadorismo e fanatismo e incrementada pela destruição ambiental. Além dessa questão das prioridades para pesquisa, o tema da sexualidade ainda gera um certo incômodo para muita gente. Tanto é que a questão do estiramento da vulva, mencionada en passant por Seeger (1981), e o estiramento dos grandes lábios vaginais, mencionado por Viveiros de Castro (1986), que eu saiba foi apenas retomada na minha pesquisa.

$\mathrm{Na}$ literatura há um caso reportado de excisão do clitóris pelos Shipibo-Conibo (Pano) no Peru. ${ }^{2}$ Em termos de variaçóes sobre um mesmo tema, valeria a pena documentar isso melhor, algo que talvez já tenha sido feito no Peru. Os homens Mebengokre perceberam a repressão do tema da sexualidade nas conversas dos brancos. Consequentemente eles se incomodavam ao me ouvir conversando com as mulheres sobre assuntos relacionados a sexualidade, tais como o estiramento dos pequenos lábios vaginais pelos homens, assuntos sobre os quais elas comentavam sem autocensura nenhuma nas idas às roças. 
Nas últimas décadas, os textos antropológicos têm sido cada vez mais lidos pelos próprios sujeitos das nossas pesquisas. Mesmo sem explicitar isso na literatura, tornou-se algo que não pode ser esquecido por quem escreve. Junto com a questão da ética, o público e o privado tampouco podem ser deixados de lado - herdado da Grécia antiga, esse binarismo está encontrando mais respaldo nos círculos antropológicos do que outros legados, tais como as noçóes de natureza, cultura e sociedade. Quando surgiu a proposta de um seminário a respeito das sexualidades indígenas (realizado no Museu Nacional em meados de 2015 e que deu origem a este texto), lembrei-me da questáo da violência doméstica entre os Maori; ${ }^{3}$ trata-se de algo que não querem discutir com interlocutores pakeha, o termo deles equivalente aos "brancos" (os não-índios). E, ao mesmo tempo, o pesquisador pode optar por não abordar suas próprias experiências sexuais no campo por considerar isso um assunto particular que náo fez parte da pesquisa em si. $^{4}$

Isso dito, considero que ainda há espaço para uma velha preocupação etnológica em reconhecer que há muitas coisas que podemos aprender com os povos ameríndios e que poderiam contribuir para modificar a sociedade ou mentalidade (mindset) euro-americana. Anos atrás, trocava ideias com Gustaaf Verswijver (que também pesquisou e conviveu longamente com os Mebengokre) a respeito da constataçáo de que a vida desse povo é permeada o tempo todo pela sexualidade. Esse etnólogo compartilhava da minha perspectiva. Em um simpósio sobre paternidade múltipla, em 1997, um participante norte-americano (James Boster) sugeriu uma escala libidinal entre os povos enfocados naquela ocasiáo, com os Mebengokre, em primeiro lugar, e os Siona-Secoya, localizados no Equador e analisados por William Vickers, em último. ${ }^{5}$ Independentemente da possibilidade de quantificar libido, a comparação feita aponta para a necessidade de evitar generalizaçôes a respeito dos povos ameríndios.

Embora seja difícil encontrar as palavras certas para expressar a realidade dos Mebengokre de forma adequada, o ato sexual, genital, é algo corriqueiro, normal, banal, rotineiro para este povo. É algo semelhante à necessidade de sono, alimento e abrigo. Foucault sintetiza uma parte de sua abordagem afirmando que sexo "junta a força de uma pulsão e a singularidade de uma história" (FOUCAULT, 1976, p. 205-206). ${ }^{6}$ Nota também que nossa civilização associa sexo com pecado há muito tempo (FOUCAULT, 1976, p. 17), afirmação que certamente náo se aplica aos Mebengokre.

Há décadas Sahlins (1972) desnaturalizou a noção de "necessidades básicas" - trata-se de uma questão sociocultural a definição de uma "necessidade" e, do ponto de vista dos(as) Mebengokre, o ato sexual é uma ne- 
cessidade básica. Certamente desvinculam o ato sexual da reprodução, algo discutido longamente por Foucault em relaçáo à criação do dispositivo da sexualidade no Ocidente, especialmente ao longo dos séculos XIX e XX. Foucault argumenta de forma convincente que "sexualidade" é um dispositivo histórico (FOUCAULT, 1976, p. 139) e que o "sexo" é um ponto ideal fixado por este dispositivo, e não uma instância autônoma (FOUCAULT, 1976, p. 205). Afirma também que "a noçáo de 'sexo' permitiu reagrupar, de acordo com uma unidade artificial, elementos anatômicos, funçóes biológicas, comportamentos, sensaçōes [e] prazeres [...]" (FOUCAULT, 1976, p. 204).

$\mathrm{Na}$ língua mebengokre, não há nada que se assemelhe a "sexualidade" latu sensu, nem a "sexo", mas os etnólogos sabem que isso não é sinônimo de falta de reconhecimento dessa noção. A família conjugal é algo intraduzível em muitas línguas ameríndias, mas é designada concretamente pela ocupação de uma determinada porção do espaço doméstico, ou por uma de suas características, tais como o "fogo", com cada família conjugal sendo demarcada por seu próprio fogo dentro das casas. Os homens Mebengokre são designados como a coletividade com pênis $\left(\right.$ memy). ${ }^{7}$ Isso não parece muito distante do que Foucault descreve como "sexo" para nossa civilização, quando afirma que: "o sexo tem funcionado como um significante único e um significado universal [...] como anatomia e como falta" (FOUCAULT, 1976, p. 204).

Em seus escritos sobre perspectivismo, Eduardo Viveiros de Castro associa as "afecções" do sujeito à sua forma corporal (1996, 2002 e passim). ${ }^{8}$ Numa analogia com as máscaras e outras "roupas animais" usadas pelos xamãs, este autor comenta que "O que se pretende ao vestir um escafandro é poder funcionar como um peixe, respirando sob a água, e não se esconder sob uma forma estranha" (VIVEIROS DE CASTRO, 1976, p. 133). Um aparato mais simples para experimentar a possibilidade de respirar abaixo da água como um peixe é o snorkel (que é também algo fálico). Por analogia, o interesse dos Mebengokre em dividir as pessoas em portadores ou não de um pênis se deve ao fato deles considerarem este marcador da diferença algo fundamental para conceitualizar as respectivas afecçóes dos homens e das mulheres, fundamentando a relacionalidade heterossexual, conforme seu ideal de complementaridade sexual, do tipo yin yang. Strathern (1988) parte da "diferença" como condiçáo sine qua non para estabelecer relaçōes, algo também enfatizado por Viveiros de Castro quando afirma que o perspectivismo ameríndio é relacional (VIVEIROS DE CASTRO, 2002, p. 383 e passim).

Citando Strathern (1988 e passim), Viveiros de Castro afirma que em uma ontologia relacional as substâncias não são a realidade última (VI- 
VEIROS DE CASTRO, 2002, p. 385), mas, ao mesmo tempo, descreve o corpo humano como "o instrumento fundamental de expressão do sujeito" (VIVEIROS DE CASTRO, 2002, p. 388; cf. VIVEIROS DE CASTRO, 1996, p. 131). Foi frisado em um artigo anterior que: "O que estou chamando de 'corpo' [...] não é sinônimo de fisiologia distintiva ou de morfologia fixa; é um conjunto de afecçóes ou modos de ser que constituem um habitus" (VIVEIROS DE CASTRO, 1996, p. 128). Viveiros de Castro, problematizando a disjunção entre humanos, animais e espíritos, deixando de lado a questão de gênero, parte de uma crítica do conceito de animismo, formulado por Descola (1986), por considerá-lo excessivamente antropocêntrico.

Paralelamente, enquanto o debate acadêmico sobre gênero vem frisando a construção sociocultural e discursiva do masculino e do feminino, o perspectivismo ameríndio evoca a complementaridade de gênero táo enfatizada na literatura etnológica. Senão vejamos: " $[\mathrm{O}]$ ponto de vista está no corpo [...] (e um ponto de vista não é senão diferença) [...] a diferença é dada pela especificidade dos corpos [...] o corpo como feixe de afecçóes e capacidades, e que é a origem das perspectivas" (VIVEIROS DE CASTRO, 1996, p. 128). Isso poderia descrever a concepção êmica de gênero não apenas para os Mebengokre; aplica-se também à maioria dos povos ameríndios e a muitos não índios.

Freud afirma que a gravata costuma simbolizar o pênis nos sonhos masculinos e insiste que não há nenhuma dúvida de que todas as armas e ferramentas são usadas como símbolos do órgão masculino, tais como martelos, rifles, revolveres, punhais, sabres etc. (FREUD, 1900, p. 821). Os Mebengokre seguram uma borduna - algo inegavelmente fálico - verticalmente entre as mãos enquanto proferem discursos formais, pontuando suas falas com batidas no chão com a ponta da borduna, em cadência com o balanço do corpo, associando virilidade a seu ethos guerreiro (mesmo de forma inconsciente nesse contexto). A ostentação pública da belicosidade masculina dos Mebengokre, os homens dançando enquanto empunham uma borduna, os tornou célebres nos meios de comunicação desde a época da Constituinte, no final da década de 1980, até os dias de hoje. Esse comportamento atesta o quão longe os Mebengokre estão da igualdade de gênero, um ideal oficial euro-americano contemporâneo que destoa da complementaridade de gênero tão destacada na produção etnológica sobre Amazônia (ver, por exemplo, McCallum, 2001).

A leitura de Foucault, após cerca de dois anos de convivência com os Mebengokre, ressoa com a dissipação do assombro da centralidade da cópula para este povo. Ao arquitetar o lento surgimento do dispositivo da sexualidade no Ocidente, a partir do século XVIII, junto com toda a com- 
plexa problemática da repressão, desembocando em sua antítese - uma obsessão pela sexualidade -, Foucault permite ao leitor viajar mentalmente a um outro mundo onde essas camadas históricas são removidas gradativamente. Além de permitir separar o ato sexual do dispositivo da sexualidade (sendo que Foucault ressalta que seu interesse é na sexualidade sem sexo [FOUCAULT, 1976, p. 200]), este autor incorpora as liçóes de Freud a respeito da sexualidade infantil, algo cuja existência o Ocidente negava até o surgimento da psicanálise.

Outro fenômeno que os Mebengokre permitem vislumbrar é a artificialidade da noção de criança. Foucault nota com propriedade que nossa civilizaçấo, por negar a sexualidade infantil, tenta afastar as crianças do assunto (FOUCAULT, 1976, p. 10). Minha experiência de campo me impressionou pelo fato de as crianças não serem afastadas da sexualidade, nem da morte, atitudes que me parecem saudáveis. No que diz respeito à morte, a participação das crianças, ao se velar e enterrar o morto, permite um fechamento psicológico e uma desvinculação mais concreta do defunto. Em relação à sexualidade infantil, Foucault sintetizou que o sexo está presente anatomicamente, mas ausente fisiologicamente, ou seja, é deficiente, se for enfocada sua finalidade reprodutiva (FOUCAULT, 1976, p. 202). Essa observaçáo poderia explicar justamente porque povos como os Mebengokre não reprimem demonstraçóes de sexualidade infantil, tais como a imitaçáo de coito, na medida em que náo transcende o nível da fantasia e, portanto, pode ser apreciado como algo engraçado pelos adultos. Foucault comenta que, nos séculos XVIII e XIX, a precocidade sexual estava associada ao risco de esterilidade, impotência etc. Isso lembra as práticas de reclusão pubertária no Alto Xingu, tais como descritas por Gregor (1977), nas quais os homens que não se submetessem aos procedimentos certos poderiam permanecer de baixa estatura, algo desvalorizado pelos Mehinacu (um povo Aruak).

Foucault demonstra admiração por Freud e pela psicanálise, mas não faz justiça a Lévi-Strauss, por não ter se aprofundado na leitura desse eminente antropólogo. Foucault afirma que o tabu de incesto chegou a ser considerado socialmente universal, como um ponto de passagem da natureza à cultura, enquanto (argumenta Foucault) a sexualidade ignora leis e formas jurídicas de aliança (FOUCAULT, 1976, p. 144). Continuando a criticar Lévi-Strauss, sem mencionar seu nome diretamente, Foucault declara que afirmar que todas as sociedades se submetem a essa "regra das regras" era uma maneira de dizer que o dispositivo da sexualidade náo poderia escapar do grande e antigo sistema de aliança (FOUCAULT, 1976, p. 144). Freud, na obra Totem e tabu (FREUD, 1912-13, p. 2.764), concorda com Frazer (1910) em relação ao tabu de incesto, dizendo que não faria 
sentido proibir algo que ninguém deseja. Freud, tal como Frazer, admitiu ser incapaz de explicar a origem do horror ao incesto (FREUD, 1912-13, p. 2.765).

Freud (FREUD, 1912-13, p. 2.784) conclui, em referência ao mito que criou acerca do parricídio como fundador da sociedade (o qual julgou ser um fato histórico), que após a morte de seu pai, os irmãos (filhos do morto) deveriam renunciar às mulheres que desejavam graças à implementação de uma lei contra o incesto. Lévi-Strauss (LÉVI-STRAUSS, 1947, p. 563) comenta que Freud não explica por que o incesto é condenado, mas por que é desejado inconscientemente. $\mathrm{O}$ antropólogo dá continuidade a esse debate enfocando a positividade do tabu de incesto, uma vez que este gera a troca (entre grupos, não entre indivíduos), base de todas as modalidades de casamento. Lévi-Strauss considerava que o casamento era indispensável à sobrevivência física no mundo "primitivo"; não se tratava de algo erótico, mas econômico, parte integrante de um sistema de reciprocidade. Acoplado a uma divisão sexual de trabalho, o casamento instaura a interdependência entre os homens e as mulheres. Parafraseando Lévi-Strauss, as alianças matrimoniais constituem coletivos, não famílias - no sentido da moderna família burguesa, tão bem descrita por Engels (1884).

Conforme apontei em 2010, Lévi-Strauss, na obra Les Structures elementaires de la parenté (1947), argumentou que:

[...] tudo que é universal remete à biologia, portanto, não se trata de um tema relevante aos antropólogos. Para este autor, sabemos que estamos no domínio sociocultural ao lidar com regras, o tabu de incesto sendo justamente a única regra universal, a excepcionalidade explicada pelo fato de que o conteúdo daquilo considerado incesto varia de uma sociedade para outra. (LEA, 2010, p. 28)

Foucault afirma que o dispositivo de aliança visa a homeostase do corpo social, que serve para sua manutenção, enquanto a sexualidade lida com prazeres e sensaçóes corporais (FOUCAULT, 1976, p. 140-141). Insiste que a aliança está ligada à economia devido ao papel que desempenha na transmissão e circulação de riqueza (FOUCAULT, 1976, p. 142) e que, a partir do século XVIII, se passou gradativamente da problemática da relação àquela da "carne" (chair), ou seja, o corpo, sensações, prazeres, concupiscência e às formas sutis de delícias e de consentimentos (FOUCAULT, 1976, p. 142). Há um viés "evolucionista" nessas afirmações, na medida em que Foucault argumenta que o dispositivo de aliança "perdeu sua importância, quando os processos econômicos e as estruturas políticas não conseguiram mais encontrar nele um instrumento adequado ou apoio suficiente" (FOUCAULT, 1976, p. 140). 
Em suma, Foucault insiste na substituição do dispositivo de aliança pelo dispositivo da sexualidade. Isso evoca críticas dirigidas a Lévi-Strauss (1983, 1984), por conta de este ter sugerido que as sociétés à maisons surgiram quando os mecanismos de parentesco e aliança não mais davam conta dos interesses políticos e econômicos. Carsten e Hugh-Jones (1995), por exemplo, chamam atenção para esse viés evolucionista de Lévi-Strauss na introdução da coletânea que organizaram sobre casas. Parafraseando Lévi-Strauss, dizem que sociedades de casas existem "num mundo ainda ordenado e concebido em termos de parentesco, mas com interesses econômicos e políticos ganhando cada vez mais importância, mesmo se ainda não superam os "laços de sangue"' (CARSTEN; HUGH-JONES, 1995, p. 9). É questionável a existência de uma sociedade pré-econômica e pré-política, mas essa questão extrapola este artigo.

A atribuição, por Lévi-Strauss, da gênese da sociedade ao tabu de incesto foi criticada por Dumont (1971) como uma espécie de mito lévi-straussiano das origens da cultura, notando que não deve ser confundido com os inúmeros exemplos empíricos da troca de mulheres em todos os continentes. O modelo lévi-straussiano permanece inalterado nos casos onde são as mulheres que trocam homens, como argumentei ser o caso entre os Mebengokre (2012), da perspectiva das matricasas uxorilocais. Lévi-Strauss não estava preocupado com a sexualidade, afirmando que as sociedades têm diversas maneiras de resolver a questão de gratificação sexual (LÉVI-STRAUSS, 1947, p. 45), notando que o desejo por relaçóes sexuais com a mesma parceira tende a se arrefecer com a passagem do tempo (LÉVI-STRAUSS, 1947, p. 36).

$\mathrm{Na}$ opinião de Foucault, ao criar o elemento ideacional de "sexo", o dispositivo da sexualidade criou o desejo por sexo, articulando-o em discurso e como verdade. Os Mebengokre e outros ameríndios valorizam o sexo genital, sem recurso ao dispositivo da sexualidade. Peter Gow (1991) levantou a questão de "gendered desires" (desejos próprios a cada gênero) na tentativa de refinar a hipótese de Janet Siskind (1973) a respeito da troca de "sexo" por "carne". Tal refinamento náo resolve a questão, mas certamente há assimetria(s) entre o desejo por sexo nos homens e nas mulheres, e há também a questão de poder. A dependência das mulheres em relação aos homens para obter bens industrializados incrementa o desejo delas pelos homens. E como já notou Bruna Franchetto (1996), a adrenalina produzida pelo perigo dos encontros proibidos é excitante em si, independentemente do sexo.

O livro de José Miguel Olivar Neto (2013), sobre a história de quatro prostitutas brasileiras militantes, menciona que suas interlocutoras achavam "trouxas" as mulheres que têm relaçôes sexuais "de graça". 
Isso coincide com o ponto de vista dos Mebengokre de ambos os sexos, conforme já discuti alhures (LEA, 1994, p. 104). Este aspecto assimétrico mereceria ser melhor aprofundado. Adriana Piscitelli (2013), no contexto do debate sobre o tráfico de mulheres, é uma das autoras que demonstra existir um grau de permeabilidade entre prostituição e sexo em troca de benefícios próprios, evidenciando que a antítese consagrada socioculturalmente entre a prostituta e a dona de casa é menos radical do que os setores conservadores tentam nos convencer.'

O tema do erotismo ainda está muito incipiente na etnologia ameríndia. No século XIX, o psicólogo Havelock Ellis (1897), estudioso da sexualidade humana, comentou que o famoso cinto de uluríno Alto Xingu é mais erótico do que seria a nudez total. Atualmente, as mulheres Mebengokre usam calcinhas para dançar em público como sinal de civilização, sem nenhuma conotação de erotismo. Enfim, o erótico e a ocorrência ou não de orgasmo feminino estáo entre os temas ainda pouco desenvolvidos na literatura, tal como a atração por parceiros brancos, não pelo seu desempenho sexual, mas pela possibilidade de acesso a bens industrializados que podem providenciar.

Foucault desenvolveu uma crítica ao puritanismo do mundo ocidental, sendo que o primeiro volume da História da sexualidade (1976) foi publicado antes do surgimento da AIDS na década seguinte. A epidemia de AIDS reanimou um furor contra o sexo, disseminando medo em uma escala sem antecedentes. Atualmente, de acordo com alguns meios de comunicação brasileiros, o risco de contaminação por AIDS está aumentando devido à diminuição desse medo pelas novas geraçôes que se preocupam menos com essa doença, por considerá-la uma doença curável e devido à falta de hábito do uso da camisinha por pessoas da terceira idade.

Em vez de tratar os indígenas como "coitadinhos", necessitados de ensino, de "benefícios" e de projetos, povos como os Mebengokre permitem desvendar nossos olhos perante os méritos da fruição da sexualidade, problematizando o clima de repressão melhor exemplificado pelos proponentes de abstinência antes do casamento nos EUA. As sociedades ditas "primitivas" têm uma longa associação com a promiscuidade no imaginário ocidental. Isso acaba provocando receio em relação a divulgar a apreciação por sexo de povos como os Mebengokre. Estes não precisam de "especialistas sexuais pagas", uma expressáo de Werner (1985) comentada por Bellier (1993), pois a atividade sexual é acessível a todos. Se fosse admitida a legitimidade da profissão milenar da prostituição na nossa sociedade, talvez houvesse menos assédios sexuais e estupros. ${ }^{10}$

Foucault faz uma reconstruçáo brilhante do surgimento do dispositivo da sexualidade no mundo ocidental, especialmente ao longo dos séculos 
XIX e XX, mas poderia ser tachado de "romântico" na medida em que opóe aliança matrimonial à sexualidade, como se as pessoas tivessem que arrebentar as manilhas das redes de aliança matrimonial para deixar florescer sua sexualidade. Ele nota o aspecto ilusório da ideia de libertação sexual, mas ao mesmo tempo vê com olhos positivos as conquistas de prazeres individuais e homoafetivos, associando-os à superaçáo da aliança pelo dispositivo da sexualidade. Parece interessante repensar essa afirmação à luz do "casamento gay", que se tornou possivelmente a principal bandeira dos movimentos LGBT no Ocidente contemporâneo. ${ }^{11}$

A forte influência evangélica experimentada no Brasil contemporâneo mergulhou o país em uma onda de conservadorismo que torna problemático abordar temas mais polêmicos, tais como o que Bamberger (1974) designa como estupro coletivo, interpretado por Crocker (1994) como sexo seriado que pode ser prazeroso para as mulheres. Acabei, neste artigo, me limitando ao primeiro volume da obra de Foucault. Enquanto etnóloga, foi impossível resistir ao apelo da defesa de Lévi-Strauss perante as investidas de Foucault. Este autor é vindicado - parcialmente - no Brasil Central devido a sua apreciação pelos prazeres do corpo, mas não quando considera que a sexualidade desbancou a aliança.

\section{Agradecimentos}

Agradeço os Mebengokre por ter compartilhado seu cotidiano e sua filosofia de vida comigo, seja na convivência nas aldeias, seja nas visitas às cidades, no decorrer dos últimos 39 anos. Agradeço a Julia Lea de Toledo pelas sugestôes, a Clara Flaksman pela revisão do português, a Andrés Pablo Salanova pelas sugestóes a respeito da língua mebengokre, e a Diego Madi Dias pelas sugestóes a respeito do texto. Sou grata às diversas agências de fomento à pesquisa que possibilitaram esta pesquisa ao longo das décadas, como o CNPq, Fundação Wenner-Gren, FINEP e FAPESP.

\section{Notas}

1. A acentuação do etnônimo Mebengokre varia tanto de um autor para outro, ocasionando tantos problemas na impressão das fontes, que optei por omitir qualquer acento.

2. Ver Françoise Morin e Bernard Saladin d'Anglure (2007).

3. O assunto surgiu em uma reunião na Unicamp com uma delegação da Universidade de Auckland. Para uma referência escrita à violência doméstica Maori ver Hoeata, Chloe et al 2011.

4. Alguns autores que abordaram essa questão são Kulick e Wilson (1995) e Markowitz e Ashkenazy (1999). 
5. Simpósio: "Paternidad Compartida", organizado por Stephen Beckerman e Paul Valentine, $49^{\circ}$ Congresso Internacional de Americanistas, Quito, Equador, 7-11 de julho, 1997. Os Airo-Pai no Peru, pesquisados por Luisa Elvira Belaunde (2001 e passim), são aparentados aos Siona-Secoya do Equador. Essa autora esclareceu (comunicação pessoal) que no passado se tratava mais de uma questão de sucessivos resguardos do que de libido propriamente dita.

6. As traduçôes do francês para português de citaçôes desta obra são minhas.

7. O linguista Andrés Pablo Salanova esclarece que memy significa: "both 'people's penises' and 'males (people with penises)'” (SALANOVA, 2013, p. 287); é o contexto que esclarece essa ambiguidade. Em correspondência com Salanova, este me advertiu para não confundir ni, designando "mulheres", com o verbo "copular", ninh. Em mebengokre, a expressão onomatopeica "txoko txoko" é também usada para designar o ato sexual.

8. O que se entende por afecçôes (do latim affectus) é uma questão filosófica complexa que ultrapassa o âmbito deste artigo. Cito, a seguir, uma nota da tese de Diego Madi Dias: "Em sintonia com o material Guna e ameríndio, utilizo afecção no sentido proposto na Ética de Spinoza (1677: III, def. 3), desenvolvido posteriormente por Bergson (1896) e, em seguida, por Deleuze \& Guatarri (1980). De acordo com essa perspectiva, os afetos se referem à experiência somática como maneira de modular a potência de agir e a potência de pensar" (DIAS, 2015, p. 29, nota 32). Ver também o verbete "affect" na versão da Wikipédia em inglês, disponível em: <https:// en.wikipedia.org/wiki/Affect_(philosophy)>. Acessado em: 20/4/2016.

9. Ver também a discussão de Bloch e Parry (1989).

10. Em um artigo sobre casamento na Grécia antiga, Vernant cita Démosthenes, um político do século IV antes de Cristo, explicando que: "Temos cortesãs para prazer; concubinas para os cuidados cotidianos; esposas para ter filhos legítimos e como guardiás fiéis das coisas da casa" (VERNANT, 1974 , p. 60) [tradução do francês minha]. Foucault, no volume 2 da História da sexualidade, usa essa mesma citação para esclarecer que na pólis grega a tematização do prazer sexual dizia respeito exclusivamente aos homens.

11. Agradeço a Diego Madi Dias por me sugerir esta última observação.

\section{Referências bibliográficas}

BAMBERGER, Joan. The Myth of Matriarchy: why men rule in primitive society. In: ROSALDO, M.; LAMPHERE, L. (Org.). Women, Culture and Society. Stanford: University Press, 1974.

BECKERMAN, Stephen; Paul VALENTINE (Org.). Cultures of Multiple Fathers: the theory and practice of partible paternity in Lowland South America. Gainesville: Editora da Universidade de Florida, 2002. 
BELLIER, Irène. Reflexions sur la Question du genre dans les sociétés amazoniennes. L'Homme, XXXIII, n. 126-128, p. 517-526. 1993.

BELAUNDE, Luisa Elvira. Viviendo bien: gênero y fertilidad entre los Airo-Pai de la Amazonía Peruana. Lima: CAAP/BCRP, 2001.

BLOCH, Maurice; PARRY, Jonathan. (Org.). Money and the Morality of Exchange. Cambridge: Cambridge University Press, 1989.

CARSTEN, Janet; HUGH-JONES, Stephen. (Org.). Introduction. In: About the House: Lévi-Strauss and beyond. Cambridge: CUP, 1995.

CROCKER, William H.; CROCKER, Jean. The Canela: bonding through kinship, ritual, and sex. Fort Worth: Harcourt Brace College Publishers, 1994.

DESCOLA, Philippe. La Nature domestique: symbolisme et praxis dans l'écologie des Achuar. Paris: Éditions de la Maison des Sciences de l'Homme, 1986.

DUMONT, Louis. Introduction à Deux théories d'anthropologie. Paris: Mouton, 1971.

ELLIS, Havelock. Studies in the Psychology of Sex (vol. 1). In: Project Gutenberg online e áudio-livro no site LibriVox.org, 1897. Disponível em: <https:// librivox.org/studies-in-the-psychology-of-sex-volume-one-by-havelock-ellis/>. Acessado em: 20/04/2016.

ENGELS, Frederick. The Origin of the Family, Private Property, and the State. New York: Pathfinder Press, 1972 (1884).

FRANCHETTO, Bruna. Mulheres entre os Kuikúro. Revista de estudos feministas, IV: 1, p. 35-54. 1996.

FOUCAULT, Michel. Histoire de la Sexualité (vol. 1): la volonté de savoir. Paris: Gallimard, 1976.

História da sexualidade (vol. 2): o uso dos prazeres. Rio de Janeiro: Graal, 1998 (1984).

FREUD, Sigmund. Complete Works. Ivan Smith (org.). Rio de Janeiro: Imago epub, 2011 (1900).

. The Interpretation of Dreams. In: Complete works. Rio de Janeiro: Imago epub, 2011 (1900).

. Totem \& Taboo. In: Complete works. Rio de Janeiro: Imago epub, 2011 (1912-13).

GREGOR, Thomas. Mehinaku: the drama of daily life in a Brazilian Indian Village. Chicago: University of Chicago Press, 1977.

Anxious Pleasures: the sexual lives of an Amazonian people. Chicago: University of Chicago Press, 1985.

GOW, Peter. Of Mixed Blood: kinship and history in Peruvian Amazonia. Oxford: Clarendon Press, 1991.

HOEATA, Chloe; NIKORA, Linda Waimarie; LI, Wendy; YOUNG-HAUSER, Amanda; ROBERTSON, Neville. Māori women and intimate partner violence: some sociocultural influences. MAI Review, n. 3. 2011. Disponível em: 
<http://www.review.mai.ac.nz/index.php/MR/article/viewFile/443/683>. Acessado em: 23/08/2015.

KULICK, Don; WILSON, Margaret. (Org.). Taboo, Sex, Identity \& Erotic Subjectivity in Anthropological Fieldwork. Routledge, 1995.

LEA, Vanessa. Gênero feminino Mebengokre (Kayapó): desvelando representaçôes desgastadas. Cadernos Pagu (3), Campinas: Núcleo de Estudos de Gênero/Unicamp, p. 85-116. 1994.

. Desnaturalizando gênero na sociedade Mebengokre. Dossiê Mulheres Indígenas. Revista de Estudos Feministas, v. 7, n. 1 e 2, p. 176-194. 1999. Multiple Paternity amongst the Mebengokre (Kayapó, Jê) of Central Brazil. In: BECKERMAN, S.; VALENTINE, P. (Org.). Cultures of Multiple Fathers: the theory and practice of partible paternity in Lowland South America. Gainesville: Editora da Universidade de Florida, 2002.

A terminologia de parentesco enquanto uma elaboração sócio-cultural da percepção do dimorfismo humano. In: AMADO, R. de Sá. (Org.). Estudos em linguas e culturas Macro-Jê. São Paulo: Editora Paulistana, 2010. p. 27-44.

Riquezas intangiveis de pessoas partiveis: os Mebêngôkre (Kayapó) do Brasil Central. São Paulo: Edusp/Fapesp, 2012.

O som do silêncio. Cadernos Pagu - Debate: Alteridade, gênero, sexualidade, afeto - Campinas: Unicamp/Pagu, n. 41, p. 87-93, jul./dez. 2013.

LÉVI-STRAUSS, Claude. Les Structures elementaires de la parenté. Paris: Mouton, 1967 (1947).

. Histoire et ethnologie. Annales, v. 38, n. 1217-1231, 1983.

Paroles Données. Paris: Plon, 1984.

MADI DIAS, Diego. Gênero disperso: estética e modulação da masculinidade Guna (Panamá). Rio de Janeiro, 2015. Tese (Doutorado no Programa de Pós-Graduação em Sociologia e Antropologia) - Instituto de Filosofia e Ciências Sociais, Universidade Federal do Rio de Janeiro.

MARKOWITZ, Fran; ASHKENASY, Michel. Sex, Sexuality and the Anthropologist. Urbana: University of Illinois Press, 1999.

MATHIEU, Nicole-Claude (Org.). Une Maison sans fille est une maison morte. Paris: Maison des sciences de l'homme, 2007.

MCCALUM, Cecilia. Gender and Sociality in Amazonia. Oxford: Berg, 2001.

MORIN. Françoise; Bernard Saladin d'anglure: excision féminine/incision masculine ou la construction sociale de la personne chez les Shipibo-Conibo d'Amazonie péruvienne. In: MATHIEU, N. (Org.). Une Maison sans fille est une maison morte. Paris: Maison des sciences de l'homme, 2007.

OLIVAR. José Miguel Nieto. Devir puta: políticas da prostituição de rua na experiência de quatro mulheres militantes. Rio de Janeiro: Ed. UERJ, 2013.

ORTNER Sherry. Interview. Anthropology of this Century (AOC). n. 12, jan. 
Post-feminism and other historical conundrums. http://aotcpress.com/articles/postfeminism-historical-condundrums/2015. Acessado em:20/04/2016. PISCITELI, Adriana. Trânsitos: brasileiras nos mercados transnacionais do sexo. Rio de Janeiro: Ed. UERJ, 2013.

SAHLINS, Marshall. Stone Age Economics. London: Tavistock, 1974 (1972).

SALANOVA, Andrés Pablo. Event Nominals in Mebengokre and the Theory of Nominalizations. Canadian Journal of Linguistics/Revue de linguistique, 58(2), p. 267-292. 2013.

SEEGER, Anthony. Nature and Society in Central Brazil: the Suyá indians of Mato Grosso. Cambridge MA: Harvard Univ. Press, 1981.

SISKIND, Janet. To Hunt in the Morning. Oxford: Oxford University Press, 1973.

VERNANT, Jean-Pierre. Mythe et société en Grèce Ancienne. Paris: Maspero, 1974.

VIVEIROS DE CASTRO, Eduardo. Araweté: os deuses canibais. Rio de Janeiro: Zahar/ANPOCS, 1986. 1996.

Os pronomes cosmológicos e o perspectivismo ameríndio. Mana II (2),

Perspectivismo e multinaturalismo na américa indígena. In: $A$ inconstância da alma selvagem (e outros ensaios de antropologia). São Paulo: Cosac Naify, 2002.

WERNER, Dennis. Paid Sex Specialists among the Mekranoti. Journal of Anthropological Research, 40 (3). 1985.

\section{autora Vanessa Rosemary Lea}

Professora Titular Colaboradora do Programa de Pós-Graduação em Antropologia Social (PPGAS) do Instituto de Filosofia e Ciências Humanas (IFCH) e uma das fundadoras do Centro de Pesquisa em Etnologia Indígena (CPEI) no IFCH.

Recebido em 27/11/2015 Aceito para publicaçáo em 05/02/2016 